\section{Inheritance of a Partial Chlorophyll Deficiency in Watermelon Activated by Low Temperatures at the Seedling Stage}

\author{
R. Provvidenti \\ Cornell University, Department of Plant Pathology, New York State Agricultural \\ Experiment Station, Geneva, NY 14456
}

Additional index words. Citrullus lanatus, chlorophyll deficiency, cold sensitivity, cold resistance, $P g i-2^{2}$

\begin{abstract}
Seedlings of watermelon [Citrullus lanatus (Thunb.) Matsum \& Nakai] are commonly affected by a partial chlorophyll deficiency that is activated by low temperatures $(<20 \mathrm{C})$, causing foliar symptoms and growth retardation. Cotyledons appear whitish-green, whereas the first leaves display a mosaic-like variegation consisting of scattered white flecks and patches. While this disorder is common in commercial watermelon cultivars, some land races from Zimbabwe appeared to be unaffected. From cross and backcross populations of the cold-sensitive cultivar New Hampshire Midget with the cold-resistant line PP261-1 (from PI 482261), the leaf variegation was determined to be conferred by a single recessive gene. The symbol $s l v$ (seedling leaf variegation) is assigned to this factor. The dominant allele at this same locus can be exploited for the development of new "cold-resistant" cultivars and $F_{1}$ hybrids, thus providing economic gain due to earlier planting.
\end{abstract}

Watermelon seedlings exposed to temperatures $<20 \mathrm{C}$ are commonly affected by a disorder that interferes with normal chlorophyll development. Cotyledons appear whitishgreen, and the first leaves display a mosaiclike variegation consisting of scattered flecks and patches deficient in chlorophyll. If low temperatures persist, young plants can be prominently affected by foliar symptoms, malformation, and growth retardation. Some cultivars appear to be more affected than others, hence, varietal reaction is an important factor. At temperatures ranging from 5 to $20 \mathrm{C}$, the initial growth of some lines is affected by a diffuse yellowing, while other lines respond with varying degrees of white mottle.

These symptoms could be easily attributed to a seedborne virus infection, but a close scrutiny of foliar mosaic reveals sharply bordered, irregular, whitish patches or islands (Fig. 1) that are similar to those associated with heritable chlorophyll deficiencies in other crops (Zaumeyer and Thomas, 1957). Affected watermelon plants eventually recover fully, but the initial slow growth may delay harvesting for a few weeks. This watermelon sensitivity to ambient temperature is a major factor in determining planting dates wherever this crop is cultivated.

During Winter 1988, while a collection of 57 plant introductions (PIs) of Citrullus lanatus fromZimbabwe (Toll and Gwaranzimba, 1983) was being analyzed for viral resistance (Provvidenti, 1991), it was noted that plants of

\footnotetext{
Received for publication 22 Apr. 1993. Accepted for publication 18 Apr. 1994. The cost of publishing this paper was defrayed in part by the payment of page charges. Under postal regulations, this paper therefore must be hereby marked advertisement solely to indicate this fact.
}

$67 \%$ of these lines were prominently affected by foliar mosaic-like variegation and stunting. Under the same conditions, the remaining $33 \%$ of those lines developed normally. To confirm these results, the Zimbabwean collection and 20 domestic cultivars were tested under controlled conditions in growth chambers. Seedlings of every line exposed to 28 to $30 \mathrm{C}$ developed normal growth. At 15 to $18 \mathrm{C}$, seedlings of 38 PI lines and 20 commercial cultivars showed varying degrees of foliar mosaic, malformation, and stunting, while those of 19 PI lines developed normally (Provvidenti, 1992). The availability of watermelon lines free of symptoms offered the opportunity to elucidate the genetics of the mosaic-like variegation activated by low temperatures (cold sensitivity) and its absence (cold resistance).

\section{Materials and Methods}

Inheritance studies were based on crosses and backcrosses between the cold-sensitive cultivar New Hampshire Midget (NHM) with the cold-resistant line PP261-1, a single-plant selection of PI 482261. These genetic populations were available from a concomitant study involving the inheritance of resistance to the Florida strain of zucchini yellow mosaic virus (ZYMV-FL) also found in PP261-1 (Provvidenti, 1991). The Zimbabwean PI 482261 included plants resistant and susceptible to ZYMV-FL, but all plants were free of symptoms at low temperatures. Plants of PP261-1 also possess the gene for the isozyme $P g i-2^{b}$ or Pgi-2 ${ }^{2}$ (Benscher and Provvidenti, 1991; Henderson, 1991; Provvidenti, 1991).

Cold tests were conducted during January and February in an insect-free greenhouse, where temperatures ranged from 15 to $18 \mathrm{C}$. Plant growth and foliar symptoms were more prominent on greenhouse plants than on those kept in a growth chamber maintained at the same temperature with a much lower light intensity.

\section{Results and Discussion}

Plants of $\mathrm{F}_{1}(\mathrm{PP} 266-1 \times \mathrm{NHM})$ and $\mathrm{F}_{1}(\mathrm{NHM}$ $x$ PP261) were free of symptoms (Table 1). Resulting $\mathrm{F}_{2}$ populations of these crosses segregated in a ratio of 3 normal : 1 with foliar variegation. Plants of $\mathrm{F}_{1} \times \mathrm{NHM}$ segregated 1 normal : 1 variegated, whereas all plants of $F_{1}$ x PP261-1 were normal. Hence, it was evident that the leaf variegation or mosaic-like disorder caused by a partial chorophyll deficiency, activated by low temperature, was conferred by a single recessive gene. To this factor, which is not cytoplasmically inherited, the

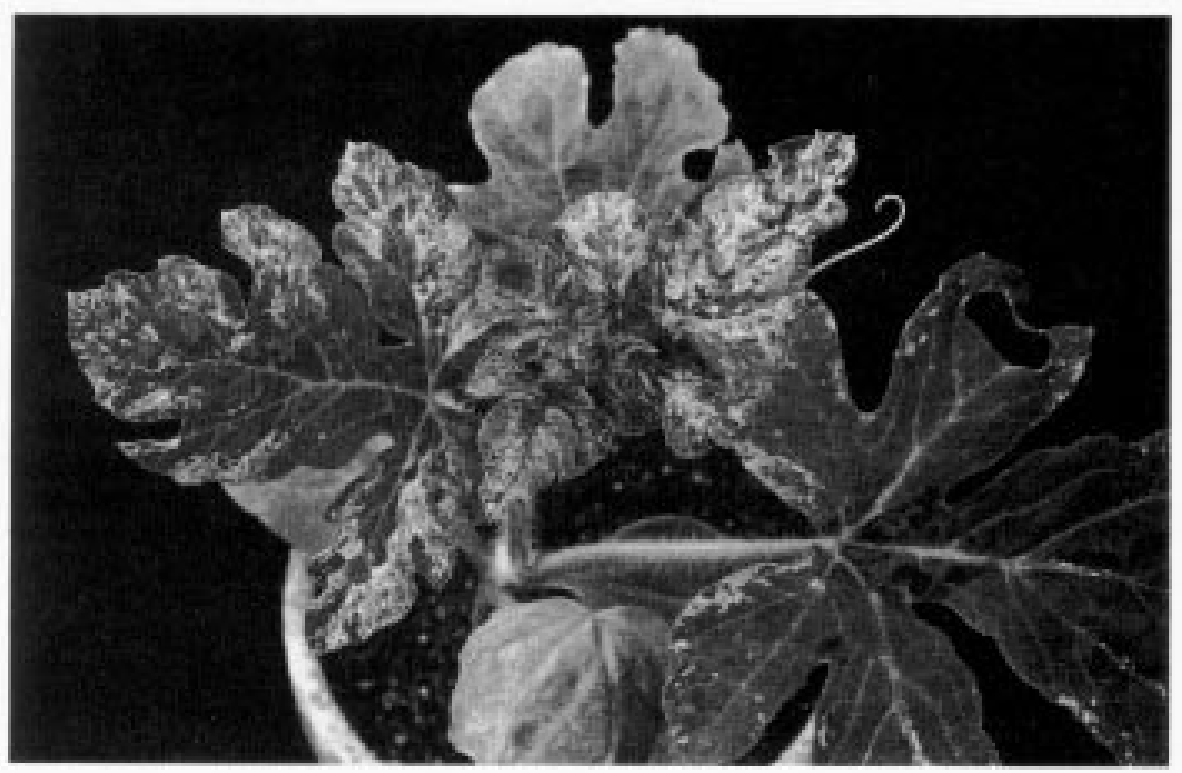

Fig. 1. A young plant of the watermelon cultivar New Hampshire Midget, growing at 15 to $18 \mathrm{C}$, showing mosaic-like foliar variegation due to partial chlorophyll deficiency. 
Table 1. Inheritance of a partial chlorophyll deficiency occurring in seedlings of Citrullus lanatus 'New Hampshire Midget' (NHM) crossed with normal plants of PP261-1, a single-plant selection of PI 482261 (Zimbabwe).

\begin{tabular}{|c|c|c|c|c|c|}
\hline \multirow[b]{2}{*}{ Progeny } & \multicolumn{2}{|c|}{ No. plants } & \multirow{2}{*}{$\begin{array}{c}\text { Expected } \\
\text { ratio } \\
(\mathrm{N}: \mathrm{S}) \\
\end{array}$} & \multirow[b]{2}{*}{$\chi^{2}$} & \multirow{2}{*}{$\begin{array}{c}\text { Goodness } \\
\text { of fit } \\
P \\
\end{array}$} \\
\hline & Normal & Sensitive & & & \\
\hline NHM & 0 & 67 & & & \\
\hline PP261-1 & 48 & 0 & & & \\
\hline \multicolumn{6}{|l|}{ NHM x PP261-1 } \\
\hline $\mathrm{F}_{1}$ & 37 & 0 & & & \\
\hline \multicolumn{6}{|l|}{ PP261-1 x NHM } \\
\hline $\mathrm{F}_{1}$ & 82 & 0 & & & \\
\hline $\mathrm{F}_{2}$ & 63 & 17 & $3: 1$ & 0.600 & 0.45 \\
\hline $\mathrm{BC}\left(\mathrm{F}_{1} \times \mathrm{NHM}\right)$ & 38 & 33 & $1: 1$ & 0.352 & 0.57 \\
\hline $\mathrm{BC}\left(\mathrm{F}_{1} \times \mathrm{PP} 261-1\right)$ & 59 & 0 & & & \\
\hline
\end{tabular}

symbol $s l v$ (seedling leaf variegation) is assigned.

During a previous study, using similar genetic populations, the resistance to ZYMV-FL was also conferred by the single recessive gene (zym), which was not linked to isozyme gene Pgi-2 ${ }^{2}$ ( Provvidenti, 1991). Therefore, another attempt was made to determine whether $P g i-2^{2}$ could be used as a marker for $s l v$. Each plant of the backcross population of NHM $x$ (PP261-1 x NHM) was scored for visible foliar symptoms at 15 to $18 \mathrm{C}$ and then analyzed for $P g i-2^{2}$. The 71 plants from this test cross segregated as follows: 20 were $P g i-2^{2} /+$ and $s l v / s l v$ (foliar variegation or cold sensitivity); 17 possessed $P g i-2^{2} /+$ and $s l v /+$ (lack of foliar variegation or cold resistance); 12 contained $+/+$ and $s l v / s l v$ (foliar variegation or cold sensitivity); and 22 were $+/+$ and $s l v /+$ (lack of foliar variegation or cold resistance). An analysis of these data showed the two genes to be independently inherited $(P=0.33)$. While no detectable linkage between $s l v$ and $P g i-2^{2}$ occurred, this isozyme was a valuable marker in determining whether some of the populations resulted from true crosses.

The absence or presence of $s l v$ in heterozygous condition $(s l v /+)$ assures freedom of symptoms on seedlings exposed to low temperatures. Thus, the dominant allele at that locus is responsible for cold resistance. This factor can be easily exploited for the production of new cultivars or $\mathrm{F}_{1}$ hybrids. When some known $s l v / s l v$ commercial cultivars ('Charleston Gray', 'Crimson Sweet', 'Dixielee', 'Jubilee', 'Kleckley Sweet', 'Mickilee', 'Minilee', 'Sugar Baby', and others) were crossed with PP261-1 plants $(+/+)$, all resulting $\mathrm{F}_{1}$ plants $(s l v /+)$ were free of leaf variegation when grown at 15 to $18 \mathrm{C}$. In addition, tests conducted near Cairo, Egypt, in Winter 1991 clearly demonstrated the value of this cold resistance. During an early February visit that year to a nonheated, highly ventilated greenhouse, plants of PP261-1, $\mathrm{F}_{1}$ (PP261-1 XNHM), and $\mathrm{F}_{1}(\mathrm{NHM} \times \mathrm{PP} 261-1)$ were 45 to $60 \mathrm{~cm}$ tall, dark green, and growing vigorously. Under the same conditions, plants of NHM and those of the local leading cultivar Giza 21 averaged 15 to $25 \mathrm{~cm}$ tall. Their leaves exhibited a diffuse yellowing, while a mosaic-like pattern was still visible on the first three to four leaves. Growth retardation due to low temperatures was clearly affecting the size of cold-sensitive plants. The greenhouse temperatures ranged from 6 to $10 \mathrm{C}$ during the night and 14 to $20 \mathrm{C}$ during the day. These data derived from 30 plants of each of the five watermelon lines, seeds of which were planted in mid-Dec. 1990.

The watermelon collection from Zimbabwe offers a range of plant sizes, leaf types, fruit characteristics, and maturity. All lines free of $s l v / s l v$, however, are landraces (primitive forms), producing vigorous plants and yielding large fruit with firm, yellowish flesh and low sugar content. In Zimbabwe, these fruit are stored for many months and used mostly for cooking and animal feeding (Toll and Gwaranzimba, 1983). Young plants of these lines are useful as rootstocks because of their large root system and apparent resistance to soil-borne diseases.

The cultivation of cold-resistant watermelon lines can secure significant economic gains if they are planted several weeks early, depending on the growing area of the world. None of the cold-resistant lines from Zimbabwe was resistant to frost. They suffered only moderate damage during the first heavy frosts but eventually succumbed to persistent temperatures $<0 \mathrm{C}$.

\section{Literature Cited}

Benscher, D. and R. Provvidenti. 1991. Allozyme diversity at the Pgi-2 locus in landraces of Citrullus lanatus from Zimbabwe. Cucurbit Genet. Coop. Rpt. 14:104-106.

Henderson, W.R. 1991. Gene list for watermelon. Cucurbit Genet. Coop. Rpt. 14:129-137.

Provvidenti, R. 1991. Inheritance of resistance to the Florida strain of zucchini yellow mosaic virus in watermelon. HortScience 26:407-408.

Provvidenti, R. 1992. Cold resistance in accessions of watermelons fromZimbabwe. Cucurbit Genet. Coop. Rpt. 15:67-68.

Toll, J. and V. Gwaranzimba. 1983. Collecting in Zimbabwe. Plant Genet. Resources Nwsl. ACP:PGR 53:2-5.

Zaumeyer, W.J. and H.R. Thomas. 1957. A monography study of bean diseases and methods for their control. U.S. Dept. Agr. Tech. Bul. 868. 